\title{
Research of E-Learning Platform of Blend Learning for Power Electronics Courses
}

\author{
Huang Lei \\ School of Automation and Electrical Engineering \\ Tianjin University of Technology and Education \\ Tianjin, China \\ Styh1225@163.com
}

\author{
Zhang Cuimin \\ School of Automation and Electrical Engineering \\ Tianjin University of Technology and Education \\ Tianjin, China \\ zhangcuimin@126.com
}

\begin{abstract}
The undergraduate power electronics course belongs to basic courses in electrical engineering. It is especially crucial for the students studying continuing subjects like control of electrical drives. Thus, a good knowledge of the various topology and control methods is needed to understand the behavior of power converter. For exploration of this knowledge-building process, a blended elearning program was developed and implemented at a college level course. An internet-based learning platform for power electronics courses was implemented. The internet accessible distant simulation system permits the instructors and students to remotely conduct simulations over the Internet. The integrated interactive multimedia material can assist the educational environment of power electronics courses. The learning outputs, such as cognitive achievement or satisfaction levels showed better comprehensive understanding of the knowledge-building process in power electronics.
\end{abstract}

Keywords - blended learning; power electronics; e-learning platform; distance laboratory

\section{INTRODUCTION}

Problems associated with teaching by the teacher and learning by the students in many universities and colleges worldwide have increased without respite given the fact that ever-increasing number of students enrolling in diverse academic programs. Face-to face lectures have become a serious problem to many educational institutions as infrastructure is reached to its limits, putting great constraint on it capability. At the same time, higher education institutions are under pressure to find new strategies and delivery models to enhance student learning. Naturally, lectures have to be complemented by other means, notably online learning to cater vast student populations. Nowadays, many universities have adopted blended learning as a solution to handle the teaching needs and learning needs of lecturers and students, respectively.

The main objective of practical training from the subject power electronics is to verify theoretical knowledge from the lectures. It is required that the students should have a good knowledge about the power electronics topology and its behavior before they enter the laboratory to measure to investigate the converter. There they learn how to understand deeper the substance of the measured converters, to avoid any damage of equipment, and to maintain safety of the work. Classical lectures and printed materials cannot offer students enough possibility to prepare themselves satisfactory for the labs. They give theoretical explanation, but the deep understanding of the converter behavior can be grasped through hands-on experimentation. Also, the time and the space available within courses on power electronics are not elastic for the verification of various modes and for checking the influence of changeable parameters of a converter on its performance and characteristics. The blended learning strategy is practiced on this course. There is no unique formula to apply for the successful development and delivery of blended learning. In this paper, the e-learning based blended learning was implemented based on e-learning. The Internet and a new generation of hardware and software applications have made e-learning emerging as one of the fastest-moving trends in higher education. Virtual laboratory has been exploited to offer the students different levels of interaction and understanding of power electronics systems. An elearning platform for power electronics courses is presented. The advantage offered by the proposed platform is that the Internet accessible distance laboratory system permits the instructor and students to remotely conduct simulations over the Internet and can be executed on any personal computer without additional hardware.

\section{BLENDED LEARNING AND E-COURSE}

The term blended learning has been widely adopted to depict combinations of face-to-face and technology-based learning [1] Blended learning is a balanced learning design with this balance achieved by the combination of classroom instruction with selfpaced instruction that is delivered over the Internet [2]. No two blended learning designs are identical, which introduces the great complexity of blended learning [3]. Blended learning, therefore, potentially offers the advantages of both traditional instruction and online learning. There is a need for a more formal approach to the development of policies and operations required in supporting blended learning approaches [4]. Blended learning may bring about major changes in the way educational material is designed,

This work was financially supported by education reform project of Tianjin University of Technology and Education, under research grant JGZ2015-03. 
developed, and delivered to people who want to access learning but have other constraints that affect the process of learning. Blended learning, therefore, potentially offers the advantages of both traditional instruction and online learning.

If one considers the delivery of blended learning to include:

(i) E-learning content. Many learning management system companies have entered the market to provide online learning solutions to many institutes of higher learning. The contents should have the functions such as centralize and automate administrative functions, use self-service and self-guided services, assemble and deliver learning content rapidly, etc.

(ii) Virtual learning environment (VLE). The aim is to build a collaborative learning environment for postgraduate research students to interact with faculty and peers to share, support, encourage, and learn from each other. The feature has the advantage of not only closing physical space and bringing everyone closer but also keeping a record of activities

(iii) Instructor-delivered content, instructor support for students. Internet-based technologies such as E-mail, QQ, Weixin have provided multiple access of e-learning content. Instructors with the ability to apply them to the blended learning will be able to provide a more positive learning environment for their students and fully enjoy their teaching experience.

(iv) Student engagement and student support.

(v) Assessment and evaluation.

It must be pointed out that there should be a balance between online learning and traditional learning and between the participant and the relationship formed with the instructor as part of any module to be delivered. The balance between online and traditional instructions and the degree of directed and independent learning will change, based on the individual's learning preferences, the material to be learned, the skills, ability, and instructional methodology of the instructor and the prior experience of the individual.

\section{E-LEARNING PLATFORM}

The e-learning platform is implemented on a PC. The proposed e-learning platform consists of a Web-based course contents, a graphical waveform display screen. The contents of this e-learning platform contain not only lecture notes and simulations but also on-line virtual experiment interface which will permit the students to learn in an interactive mode.

A typical power electronics curriculum should contain the theoretical lectures, the design and simulation exercise and the laboratory sessions. The theoretical lectures provide the background knowledge required for designing of power electronics converters. During the design and simulation exercise part, the students can learn to design their own basic converters according to a given design specification sheet. During the laboratory sessions, the students will be encouraged to build switching converters and/or compensation circuit according to the same design specification. After finished their design, the students are then encouraged to test them under various conditions.

In this paper, a power electronics e-learning platform is proposed. The objectives of this e-learning platform are to train the students to: 1) gain basic understanding of power electronics; 2) analyze and derive expected results; 3) simulate and verify the analysis; 4) validate through hardware experiments. In order to achieve these goals, course topics are designed carefully using a top-down approach where the fundamental concepts are included with illustrations of design examples [5]. To reinforce theory, all topics are tightly coupled with simulations and hardware laboratories.

Take the buck converter for example. The circuit photographs and circuit configurations are given at the template section, as shown in Fig. 10. The next part of the context includes circuit analysis related lectures. In this part, fundamental operation principles and key waveforms on the major component (switch(es), inductor(s), and capacitor(s)) will be introduced. Students can then try to calculate the values of some important parameters (duty cycle, inductor value, critical conduction mode boundary...etc) using basic operating equations. During this part, the proposed e-learning platform will assist the students in completing their design in a step-by-step way [6].

The results from the student feedback forms have been extremely positive with regard to the experiments provided in the proposed e-learning platform, the majority of students felt that such experiments enhanced their understanding of the theoretical material and made the course more interesting.

\section{CONCLUSION}

There is clear evidence that e-learning offers increased opportunities for formative assessment leading to real benefits in terms of student retention and achievement. The internet accessible distance laboratory system permits the instructors and students to remotely conduct experiments over the Internet. The web-based interactive multimedia material can assist the educational environment of power electronics courses. The advantages of the proposed platform include flexibility, provision for distance simulations and removal of laboratory time and space constraint. Positive response from students indicates that the presented platform is very useful for power electronics courses. There was evidence of improvements in pass rates and overall marks and a high degree of student engagement with the process. 


\section{REFERENCES}

[1] Stubbs M., Martin I. and Endlar L, "The structuration of blended learning: Putting holistic design principles into practice", British Journal of Educational Technology, vol. 37, no. 2(2006), pp. 163-175.

[2] Voci E. and Young K, "Blended learning in a leadership development programme”, Industrial and Commercial Training, vol. 33, no. 5(2001), pp. 157-160.

[3] Garrison D.R. and Kanuka H, "Blended learning: Uncovering its transformative potential in higher education", Internet and Higher Education, vol. 7, no. 2(2004), pp. 95-105.

[4] Pailing M, "E-learning: Is it really the best thing since sliced bread?", Industrial and Commercial Training, vol. 34, no. 4(2002), pp. 151-155.

[5] M. Trivedi, E.A. McShane, R. Vijayalakshmi, A. Mulay, S. Abedinpour, S. Atkinson, K. Shenai, "An improved approach to application-specific power electronics education-switch characterization and modeling", IEEE Transactions on Education, Vol. 45, No. 1(2002), pp. 57-64.

[6] S.A. Shirsavar, "Teaching practical design of switch-mode power supplies", IEEE Transactions on Education, Vol. 47, No. 4(2004) pp. 467-473. 